\title{
Aktivitas Anti Luka Bakar dari Gel Minyak Kemiri (Aleurites moluccana L.) terhadap Tikus Putih (Rattus novergicus)
}

\author{
Leny $^{1}$, Evi Ekayanti Ginting ${ }^{2}$, Warnus Laia ${ }^{1}$, Ihsanul Hafiz ${ }^{3}$ dan Jacub Tarigan ${ }^{3}$ \\ ${ }^{1}$ Departemen Teknologi Farmasi, Fakultas Farmasi dan Kesehatan, Insititut Kesehatan Helvetia, Medan, 20124 \\ ${ }^{2}$ Departemen Kimia Farmasi, Fakultas Farmasi dan Kesehatan, Insititut Kesehatan Helvetia, Medan, 20124 \\ ${ }^{3}$ Departemen Farmakologi, Fakultas Farmasi dan Kesehatan, Insititut Kesehatan Helvetia, Medan, 20124
}

Reception date of the manuscript: 23 Oktober 2020

Acceptance date of the manuscript: 27 Mei 2021

Publication date: 31 Desember 2021

\begin{abstract}
Candlenut oil is often used as a traditional medicine that is used topically, generally used to treat hair and treat burns. The purpose of this study was to test the anti-burn activity of candlenut oil which has been formulated in the form of a gel. The test groups were divided into blank (gel without candlenut oil), gel containing candlenut oil 15\%, 20\% and 25\% also Burnazin® ointment as the positive control. The method used was a laboratory experimental where candlenut oil was formulated in gel containing various concentrations of active substances 15, 20 and $25 \%$, then tested for burn wound healing activity in rats induced by hot plates. Observation of wound healing time was carried out for 21 days and analyzed by Anova method with p-value $95 \%$. The results showed that $25 \%$ candlenut oil gel healing percentage $(94,40 \pm 0,11 \%)$ were similar to the positive control Burnazin ${ }^{\circledR}$ in healing burn wound $(97,70 \pm 0,55 \%)$. All of the candlenut oil gel formulas were completely fulfilled the requirement for gel preparation and have activity to heal burn which is significant to blank group $(\mathrm{p}<0.05)$.
\end{abstract}

Keywords-Aleurites moluccana, burn wound healing activity, gel

\begin{abstract}
Abstrak - Minyak kemiri sering digunakan sebagai obat tradisional yang digunakan secara topikal, umumnya digunakan untuk merawat rambut dan mengobati luka bakar. Tujuan dari penelitian ini adalah menguji aktivitas anti luka bakar dari minyak kemiri yang telah diformulasikan dalam bentuk gel. Kelompok pengujian dibagi menjadi 5 yaitu kelompok blanko (gel tanpa minyak kemiri), gel minyak kemiri konsentrasi 15\%,20\% dan 25\%, serta digunakan Burnazin ${ }^{\circledR}$ sebagai kontrol positif. Sediaan diuji aktivitas anti luka bakar pada tikus yang diinduksi plat panas. Pengamatan waktu penyembuhan luka dilakukan selama 21 hari setiap minggu kemudian dianalisa menggunakan Anova dengan tingkat kepercayaan 95\%. Hasil menunjukkan gel minyak kemiri $25 \%$ memberikan hasil penyembuhan luka bakar $(94,40 \pm 0,11 \%)$ yang hampir sebanding dengan kontrol positif Burnazin ${ }^{\circledR}(97,70 \pm 0,55 \%)$ Seluruh formula gel minyak kemiri memenuhi syarat uji formula dan memiliki aktivitas dalam mengobati luka bakar dan menunjukkan hasil yang signifikan terhadap kelompok uji blanko $(\mathrm{p}<0,05)$
\end{abstract}

Kata Kunci-Aleurites moluccana, aktivitas anti luka bakar, gel

\section{Pendahuluan}

Kemiri (Aleurites moluccana L.) merupakan tanaman asli dari Asia Tenggara, khususnya di Indonesia dan Malaysia. Kemiri memiliki berbagai manfaat baik sebagai bumbu ataupun bahan makanan, bahan kosmetik dan obat tradisional. Kemiri dipercaya memiliki aktivitas farmakologis dan digunakan sebagai obat tradisional untuk mengobati asma, hepatitis, maag, sakit kepala, demam, peradangan dan antirematik (Cesca et al., 2012; Krisnawati \& Kallio, 2011; Ubeda et al., 2017).

Bagian yang sering dimanfaatkan adalah bijinya dan minyak yang diisolasi dari biji. Kandungan dari minyak kemiri

Penulis koresponden: Leny, leny @ helvetia.ac.id
TABel 1: Formula Gel Minyak Kemiri

\begin{tabular}{lcccc}
\hline \multirow{2}{*}{ Bahan } & \multicolumn{4}{c}{ Konsentrasi bahan } \\
& F0 & F1 & F2 & F3 \\
& $0 \%$ & $15 \%$ & $20 \%$ & $25 \%$ \\
\hline $\begin{array}{l}\text { Minyak biji } \\
\text { kemiri }\end{array}$ & & & & \\
Carbopol & $3 \%$ & $3 \%$ & $3 \%$ & $3 \%$ \\
HCO & $15 \%$ & $15 \%$ & $15 \%$ & $15 \%$ \\
Propilen glikol & $5 \%$ & $5 \%$ & $5 \%$ & $5 \%$ \\
Metil paraben & $0,15 \%$ & $0,15 \%$ & $0,15 \%$ & $0,15 \%$ \\
Propil paraben & $0,05 \%$ & $0,05 \%$ & $0,05 \%$ & $0,05 \%$ \\
Aquadest ad & $60 \mathrm{ml}$ & $60 \mathrm{ml}$ & $60 \mathrm{ml}$ & $60 \mathrm{ml}$ \\
\hline
\end{tabular}

antara lain hentriacontane, $\alpha$-amyrin, $\beta$-amyrin, stigmasterol, $\beta$-sitosterol dan campesterol. Senyawa tersebut merupa- 
TABEL 2: DiAMETER RATA-RATA LUKA BAKAR

\begin{tabular}{lllll}
\hline \multirow{2}{*}{ Kelompok } & \multicolumn{5}{l}{ Diameter Rata-rata Luka Bakar $(\mathrm{mm})$} \\
\cline { 2 - 5 } & Hari ke-1 & Hari ke-7 & Hari ke-14 & Hari ke-21 \\
\hline Formula 0 (Blanko) & $20,30+0,00$ & $16,10+0,87$ & $10,03+0,66$ & $6,60+0,36$ \\
Formula 1 (15\%) & $20,30+0,00$ & $15,57+0,23$ & $9,80+0,20$ & $6,43+0,45$ \\
Formula 2 (20\%) & $20,30+0,00$ & $15,83+0,85$ & $9,47+0,29$ & $5,60+0,30$ \\
Formula 3 (25\%) & $20,30+0,00$ & $15,57+0,25$ & $8,23+0,91^{*}$ & $4,80+0,10^{*}$ \\
Kontrol positif & $20,30+0,00$ & $15,63+0,21$ & $6,90+0,65^{*}$ & $3,03+0,65^{*}$ \\
\hline
\end{tabular}

Keterangan: * Berbeda signifikan terhadap kontrol negatif $(\mathrm{p}<0,05)$. Tiap kelompok terdiri atas 3 ekor hewan uji

kan senyawa fenolik yang berhasil difraksinasi menggunakan n-heksan dan etil asetat, yang merupakan senyawa nonpolar (Meyre-Silva et al., 1998). Minyak kemiri sering digunakan untuk perawatan rambut, bahan dasar cat, sabun, bahan bakar, dan untuk pengobatan seperti luka dan memar pada kulit (Martin et al., 2010; Sulistyo et al., 2008).

Dalam pengobatan tradisional minyak kemiri dipercaya mampu mengobati berbagai luka di kulit, baik luka memar, benturan, sayat dan luka bakar (Cesca et al., 2012; Yamlean et al., 2019). Gel merupakan bentuk sediaan yang mempunyai kemampuan pelepasan yang baik, memberikan efek dingin dan mempunyai efek penyebaran yang baik pada kulit dibandingkan sediaan topikal lainnya.

Gel diformulasikan dengan cara mempersiapkan seluruh bahan baku yang telah ditimbang. Carbopol sebagai bahan pembuat gel dikembangkan terlebih dahulu (Upadhyay et al., 2011). Gel dalam penelitian ini akan dibahas hasil uji aktivitas dari minyak kemiri yang telah diformulasikan dalam bentuk sediaan gel dalam menyembuhkan luka bakar pada tikus. Nilai kebaruan dari penelitian ini adalah penilaian kemampuan formula gel minyak kemiri dalam menyembuhkan luka bakar, yang belum pernah dilakukan uji sebelumnya.

\section{Alat, Bahan dan Metode}

\subsection{Bahan dan Alat}

Bahan yang digunakan dalam penelitian ini meliputi minyak kemiri (CV. Amor Chemical), carbopol, propilen glikol, hydrogenated castor oil (HCO), metil paraben, propil paraben, air suling, dan salep Burnazin ${ }^{\circledR}$ (Darya-Varia).

Alat-alat yang digunakan diantaranya adalah peralatan gelas laboratorium, timbangan analitik, timbangan hewan, plat besi berdiameter $20,3 \mathrm{~mm}$, dan jangka sorong.

\subsection{Metode}

Minyak kemiri diformulasikan dalam bentuk sediaan gel dengan berbagai konsentrasi yaitu $0,15,20$ dan $25 \%$ (F0, F1, F2, dan F3). Formula gel yang dimodifikasi dapat dilihat pada Tabel 1. Gel diformulasikan dengan cara mempersiapkan seluruh bahan baku yang telah ditimbang. Carbopol sebagai bahan pembuat gel dikembangkan terlebih dahulu menggunakan air panas di dalam lumpang, kemudian digerus hingga terbentuk konsistensi gel. Ditambahkan propilen glikol ke dalam massa gel yang telah terbentuk lalu digerus hingga homogen, kemudian ditambahkan propil paraben dan metil paraben, lalu digerus kembali hingga homogen. Minyak kemiri sebelum dicampurkan ke dalam massa gel dicampurkan terlebih dahulu dengan hydrogenated castor oil (HCO), kemudian campuran ini ditambahkan ke dalam lumpang yang berisi massa gel lalu digerus hingga homogen (Iskandar et al., 2021).
Pengujian aktivitas anti luka bakar dilakukan terhadap tikus putih dimana punggung tikus ditempelkan plat panas hingga terbentuk luka bakar sebesar 20,3 mm. Hewan uji terdiri dari 5 kelompok tikus yang disesuaikan dengan jumlah formula, yaitu kelompok kontrol diberikan F0 sebagai kontrol negatif, kelompok kedua hingga keempat diberikan F1, F2 dan F3 yaitu gel yang mengandung minyak kemiri sebesar 15, 20 dan 25\%. Kelompok kelima diberikan Burnazin ${ }^{\circledR}$ krim sebagai kontrol positif. Tiap kelompok terdiri dari 3 ekor tikus uji (total 15 ekor)

Pengamatan penyembuhan luka bakar dilakukan selama 21 hari dan diamati setiap hari ke 1, 7, 14 dan 21. Pengamatan yang dilakukan adalah bentuk luka secara kualitatif dengan mengamati warna, ada atau tidaknya terbentuk keropeng (scab), dan terbentuknya kulit baru. Secara kuantitatif diukur diameter luka dan persentase kesembuhan luka. Hasil kemudian dianalisa secara statistik menggunakan metode Anova untuk membandingkan antar kelompok dang mengetahui signifikansi kelompok uji terhadap kontrol. Nilai persentase kesembuhan luka dihitung menggunakan rumus:

$$
\text { Kesembuhan }=\left(d x 1^{2}-d x n^{2}\right) / d x 1^{2} \times 100 \%
$$

Dengan $d x 1$ adalah diameter luka hari 1 dan $d x n$ adalah diameter hari $\mathrm{n}$.

\section{HASIL}

Hasil penelitian berupa hasil berupa pengamatan diameter dan persentase kesembuhan luka dapat dilihat pada Tabel 2 dan Tabel 3, hasil pengamatan luka secara kualitatif atau visual dapat dilihat pada Tabel 4.

\section{Pembahasan}

Berdasarkan hasil pengamatan luka secara visual, dapat dinilai proses penyembuhan dari warna luka, terbentuknya scab atau keropeng hingga sampai terbentuknya lapisan kulit baru. Pada hari ke-1, semua kelompok uji menunjukkan luka bakar yang berwarna merah kecoklatan dan dengan seiring waktu berubah menjadi warna merah, merah muda hingga putih. Pada kelompok uji kontrol positif dan F3 (gel minyak kemiri $25 \%$ ) telah tampak perubahan menjadi warna merah muda namun pada kelompok lain kulit masih berwarna merah. Perubahan warna pada luka bakar menunjukkan adanya proses pembentukan kulit baru pada bagian luka (Cesca et al., 2012; Murti, 2017; Oktiarni et al., 2012; Yamlean et al., 2019). Scab atau keropeng dapat diamati pada hari ke-7. Pembentukan keropeng menunjukkan proses penyembuhan luka yang memasuki fase proliferasi tahap awal. Pada fase ini, luka diisi oleh sel-sel radang, fibroblas, serat-serat kolagen, kapilerkapiler baru yang membentuk jaringan kemerahan dengan permukaan tidak rata. Fase ini umumnya terjadi hingga hari 
Tabel 3: Persentase Rata-rata Penyembuhan Luka BaKar

\begin{tabular}{lllll}
\hline \multirow{2}{*}{ Kelompok } & \multicolumn{5}{c}{ Persentase Rata-rata Penyembuhan Luka Bakar (\%) } \\
\cline { 2 - 5 } & Hari ke-1 & Hari ke-7 & Hari ke-14 & Hari ke-21 \\
\hline Formula 0 (Blanko) & $0,00+0,00$ & $36,93+3,86$ & $75,50+1,85$ & $89,40+0,68$ \\
Formula 1 (15\%) & $0,00+0,00$ & $41,20+1,00$ & $76,67+0,55$ & $89,43+0,84$ \\
Formula 2 (20\%) & $0,00+0,00$ & $39,03+3,78$ & $78,23+0,77$ & $92,60+0,49^{*}$ \\
Formula 3 (25\%) & $0,00+0,00$ & $41,17+1,10$ & $83,40+2,02^{*}$ & $94,40+0,11^{*}$ \\
Kontrol positif & $0,00+0,00$ & $40,67+0,89$ & $88,90+1,28^{*}$ & $97,70+0,55^{*}$ \\
\hline
\end{tabular}

Keterangan: * Berbeda signifikan terhadap kontrol negatif $(\mathrm{p}<0,05)$. Tiap kelompok terdiri atas 3 ekor hewan uji

TABEL 4: HASIL PENGAMATAN LUKA BAKAR SECARA VISUAL

\begin{tabular}{|c|c|c|c|c|c|c|}
\hline \multirow{2}{*}{ Formula } & \multirow{2}{*}{ Tikus } & \multirow{2}{*}{ Keterangan } & \multicolumn{4}{|c|}{ Hasil Pengamatan Hari ke- } \\
\hline & & & 1 & 7 & 14 & 21 \\
\hline \multirow{10}{*}{ Formula 0 (kontrol negatif / blanko) } & \multirow{3}{*}{1} & Warna & MK & $\mathrm{C}$ & $\mathrm{M}$ & $\mathrm{M}$ \\
\hline & & Terbentuk scab & - & & & $\checkmark$ \\
\hline & & Terbentuk kulit baru & - & - & - & $\checkmark$ \\
\hline & \multirow{3}{*}{2} & Warna & MK & $\mathrm{C}$ & M & M \\
\hline & & Terbentuk scab & - & $\checkmark$ & $\checkmark$ & $\checkmark$ \\
\hline & & Terbentuk kulit baru & - & - & - & $\checkmark$ \\
\hline & \multirow{3}{*}{3} & Warna & MK & $\mathrm{C}$ & M & M \\
\hline & & Terbentuk scab & - & - & $\checkmark$ & $\checkmark$ \\
\hline & & Terbentuk kulit baru & - & - & - & $\checkmark$ \\
\hline & \multirow{3}{*}{1} & Warna & MK & $\mathrm{C}$ & M & M \\
\hline \multirow{8}{*}{ Formula $1(15 \%)$} & & Terbentuk scab & - & $\checkmark$ & $\checkmark$ & $\checkmark$ \\
\hline & & Terbentuk kulit baru & - & - & - & $\checkmark$ \\
\hline & \multirow{4}{*}{2} & Warna & MK & $\mathrm{C}$ & M & MM \\
\hline & & Terbentuk scab & - & $\checkmark$ & $\checkmark$ & - \\
\hline & & Terbentuk kulit baru & - & - & $\checkmark$ & $\checkmark$ \\
\hline & & Warna & MK & $\mathrm{C}$ & M & M \\
\hline & \multirow[t]{3}{*}{3} & Terbentuk scab & - & $\checkmark$ & $\checkmark$ & $\checkmark$ \\
\hline & & Terbentuk kulit baru & - & - & - & $\checkmark$ \\
\hline \multirow{9}{*}{ Formula $2(20 \%)$} & & Warna & MK & $\mathrm{C}$ & M & MM \\
\hline & \multirow[t]{3}{*}{1} & Terebentuk scab & - & $\checkmark$ & $\checkmark$ & - \\
\hline & & Terbentuk kulit baru & - & - & - & $\checkmark$ \\
\hline & & Warna & MK & $\mathrm{C}$ & M & MM \\
\hline & \multirow[t]{3}{*}{2} & Terbentuk scab & - & $\checkmark$ & $\checkmark$ & - \\
\hline & & Terbentuk kulit baru & - & - & - & $\checkmark$ \\
\hline & & Warna & MK & $\mathrm{C}$ & M & M \\
\hline & \multirow[t]{3}{*}{3} & Terbentuk scab & - & $\checkmark$ & $\checkmark$ & - \\
\hline & & Terbentuk kulit baru & - & - & - & $\checkmark$ \\
\hline \multirow{9}{*}{ Formula $3(25 \%)$} & & Warna & MK & $\mathrm{C}$ & M & MM \\
\hline & \multirow[t]{3}{*}{1} & Terbentuk scab & - & $\checkmark$ & $\checkmark$ & - \\
\hline & & Terbentuk kulit baru & - & - & - & $\checkmark$ \\
\hline & & Warna & MK & $\mathrm{C}$ & MM & MM \\
\hline & \multirow[t]{3}{*}{2} & Terbentuk scab & - & $\checkmark$ & $\checkmark$ & - \\
\hline & & Terbentuk kulit baru & - & - & $\checkmark$ & $\checkmark$ \\
\hline & & Warna & MK & M & $\mathrm{MM}$ & $\mathrm{P}$ \\
\hline & \multirow[t]{3}{*}{3} & Terbentuk scab & - & $\checkmark$ & $\checkmark$ & - \\
\hline & & Terbentuk kulit baru & - & - & $\checkmark$ & $\checkmark$ \\
\hline \multirow{9}{*}{ Kontrol positif } & & Warna & MK & $\mathrm{P}$ & M & M \\
\hline & \multirow[t]{3}{*}{1} & Terbentuk scab & - & $\checkmark$ & $\checkmark$ & - \\
\hline & & Terbentuk kulit baru & - & - & $\checkmark$ & $\checkmark$ \\
\hline & & Warna & MK & M & MM & $\mathrm{P}$ \\
\hline & 2 & Terbentuk scab & - & $\checkmark$ & - & - \\
\hline & & Terbentuk kulit baru & - & - & $\checkmark$ & $\checkmark$ \\
\hline & & Warna & MK & $\mathrm{C}$ & MM & $\mathrm{P}$ \\
\hline & 3 & Terbentuk scab & - & $\checkmark$ & $\checkmark$ & - \\
\hline & & Terbentuk kulit baru & - & - & $\checkmark$ & $\checkmark$ \\
\hline
\end{tabular}

Keterangan: Merah kecoklatan (MK); Coklat (C); Merah (M); Merah Muda (MM); Putih (P); Ada ( $\checkmark$ ); tidak ada (-)

ke-14. Kecepatan pembentukan scab atau keropeng menunjukkan kecepatan penyembuhan dari luka (Kozier, 1995). Se- mua kelompok menunjukkan pembentukan scab atau keropeng pada hari ke-7. Tiga kelompok uji menunjukkan pem- 
bentukan lapisan kulit baru pada hari ke-14 yaitu F1 (15\%), F3(25\%) dan kontrol positif.

Kemampuan penyembuhan dilakukan dengan mengukur diameter luka dan persentase kesembuhan antara masingmasing kelompok. Perbedaan antar kelompok terlihat pada kelompok formula 3 dan kontrol positif dimana pada hari ke14 dan ke-21 terdapat perbedaan yang signifikan terhadap nilai diameter luka kontrol negatif. Persentase kesembuhan luka antara kontrol negatif terhadap formula 3 dan kontrol positif juga menunjukkan adanya perbedaan yang signifikan mulai hari ke-14, dan di hari ke-21 formula 2 juga menunjukkan adanya perbedaan yang signifikan terhadap kontrol negatif.

Kemampuan gel yang mengandung minyak kemiri dalam menyembuhkan luka bakar disebabkan adanya kandungan senyawa flavonoid dan atau senyawa polifenol yang memiliki aktivitas antioksidan dan antibakteri yang berguna dalam proses penyembuhan luka (Lestari et al., 2015; MeyreSilva et al., 1998; Prabowo, 2020). Senyawa polifenol yang memiliki aktivitas antioksidan juga dapat meningkatkan proses penyembuhan dengan memicu terbentuknya lapisan kulit baru pada bagian luka (Ganesan \& Xu, 2017; Krishnaveni, 2014; Nokhala \& Siddiqui, 2020).

\section{KESIMPULAN}

Gel yang mengandung minyak kemiri sebagai bahan aktif mampu meningkatkan aktivitas penyembuhan luka bakar pada kulit tikus yang diinduksi menggunakan plat besi panas. Terjadi aktivitas penyembuhan luka bakar yang signifikan pada gel dengan konsentrasi 20 dan $25 \%$ pada hari ke14. Gel minyak kemiri konsentrasi $25 \%$ mempunyai aktivitas penyembuhan yang serupa dengan kontrol positif karena tidak terdapat perbedaan yang signifikan secara statistik $(\mathrm{p}>0,05)$.

\section{UCAPAN TERIMA KASIH}

Ucapan terimakasih disampaikan kepada Deputi Bidang Penguat Riset dan Pengembangan, Kementerian Riset dan Teknologi / Badan Riset dan Inovasi Nasional dan Lembaga Layanan Pendidikan Tinggi Wilayah I Sumatera Utara, Kementerian Pendidikan dan Kebudayaan dengan no kontrak 268/LL1/PG/2020 atas pendanaan yang diberikan sehingga penelitian ini dapat terlaksana dengan baik.

\section{Daftar Pustaka}

Cesca, T. G., Faqueti, L. G., Rocha, L. W., Meira, N. A., Meyre-Silva, C., de Souza, M. M., Quintao, N. L. M., Silva, R. M. L., Filho, V. C., \& Bresolin, T. M. B. (2012). Antinociceptive, Anti-Inflammatory and Wound Healing Features in Animal Models Treated with a Semisolid Herbal Medicine Based on Aleurites moluccana L. Willd. Euforbiaceae Standardized Leaf Extract: Semisolid Herbal. J. Ethnopharmacol., 143(1), 355-362.

Ganesan, K., \& Xu, B. (2017). A critical review on polyphenols and health benefits of black soybeans. Nutrients, 9(5), $1-17$.

Iskandar, B., Dian, Z. P., Renovita, F., Tinggi, S., Farmasi, I., \& Syafira, R. S. (2021). Formulasi dan evaluasi gel Lidah buaya ( Aloe vera Linn ) sebagai pelembab kulit dengan penggunaan carbopol sebagai gelling agent. 5(1), 1-8.
Kozier, B. (1995). Fundamental of Nursing, Conceps, Process and Practice. Boston: Adison Wesley, 4th ed.

Krishnaveni, M. R. D. (2014). Qualitative and Quantitative Study of Phytochemicals in Muntingia calabura L. Leaf and Fruit. World J. Pharm. Res., 3(6), 1687-1696.

Krisnawati, H., \& Kallio, M. (2011). Aleurites moluccana (L.) Willd. Ecology, silviculture and productivity. Bogor: Center for International Forestry Research (CIFOR).

Lestari, M. S., Himawan, T., Abadi, A. L., \& Retnowati, R. (2015). Research Article Toxicity and phytochemistry test of methanol extract of several plants from papua using Brine Shrimp Lethality Test ( BSLT ). J. Chem. Pharm. Res., 7(4), 866-872.

Martin, C., Moure, A., Martin, G., Carrillo, E., Dominguez, H., \& Parajo, J. C. (2010). Fractional Characterisation of Jatropha, Neem, Moringa, Trisperma, Castor and Candlenut Seeds as Potential Feedstocks for biodiesel production in Cuba. Biomass and Bioenergy, 34(4), 533-538.

Meyre-Silva, C., Mora, T. C., Biavatti, M. W., Santos, A. R. S., Dal-Magro, J., Yunes, R. A., \& Cechinel-Filho, V. (1998). Preliminary Phytochemical and Pharmacological Studies of Aleurites moluccana Leaves [L.] Willd. Phytomedicine, 5(2), 109-113.

Murti, D. A. (2017). Efektifitas Salep Getah Jarak Pagar (Jatropha curcas L) Pada Fase Epitelisasi Penyembuhan Luka Sayat Kulit Mencit (Mus musculus) Dengan Pewarnaan Masson Trichrome. J. Ilm. Mhs. Vet., 1(3), 465-472.

Nokhala, A., \& Siddiqui, M. J. (2020). Phytochemicals and biological activity of Tetracera scandens Linn. Merr. (Dilleniaceae): A short review. J. Pharm. Bioallied Sci., 22(3), 217-222.

Oktiarni, D., Manaf, S., \& Suripno (2012). Pengujian Ekstrak Daun Jambu Biji (Psidium guajava Linn.) Terhadap Penyembuhan Luka Bakar Pada Mencit (Mus musculus). Gradien, 8(1), 752-755.

Prabowo, W. C. (2020). Antibacterial Activity of Scopoletin from Stem Bark of Aleurites moluccana Against Salmonella typhi. J. Trop. Pharm. Chem., 5(1), 29-32.

Sulistyo, H., Rahayu, S. S., Winoto, G., \& Suardjaja, I. M. (2008). Biodiesel Production from High Iodine Number Candlenut Oil. World Acad. Sci., 48, 485-488.

Ubeda, L. C. C., Araújo, A. C., Barbalho, M. S., Bueno, P. C. d. S., Guiguer, É. L., da Silva, M., de Sousa, S., Dias, F. d. A., Luiza, A. M., Pinheiro, R. A., Marutani, V. H., \& Prando, M. (2017). Effects of the Seeds of Aleurites moluccana on the Metabolic Profile of Wistar Rats. Pharma Innov. J., 6(1), 98-103.

Upadhyay, N., Panwar, A. S., Bairagi, M., Gujar, S., Darwhekar, G., \& Jain, D. (2011). Emulgel : A Review. Asian J. Pharm. Life Sci., 1(3), 333-342.

Yamlean, P. V., Queljoe, E. D., \& Bodhi, W. (2019). Base Variations of the Candlenut Oil Ointment (Aleurites moluccana) and the Healing Potential Test on Wounds in Rabbits. J. Ilmu Kefarmasian Indones., 17(2), 232-237. 